\title{
Demanda infantil por serviços de saúde mental: sinal de crise ${ }^{1}$
}

\author{
Maria Lúcia Boarini \\ Roselânia Francisconi Borges \\ Universidade Estadual de Maringá
}

\begin{abstract}
Resumo
Este estudo é o resultado de uma reflexão sobre o significado histórico da alta demanda infantil aos serviços de saúde mental na rede pública de saúde. Através da literatura produzida sobre o tema infância, buscamos recuperar aspectos concernentes à sua constituição enquanto produção social. Pontuamos a existência de uma crise para a infância - enquanto categoria histórica - na pós-modernidade e destacamos algumas rupturas presentes no "pensar" sobre a infância. Ao nos referirmos a todas as crianças como "crianças em si" ", negamos que a grande maioria delas são tratadas como "crianças tão somente"3 ou seja, apenas pelo dado da maturação biológica. Identificamos que tal crise, para as "crianças tão somente" - pertencentes às classes populares - não é exclusiva da era pós-moderna. $\quad$ Saúde pública.

Palavras-chave: Infância, Saúde
\end{abstract}

Key-words: Childhood, Juvenile mental health, Public health care.

\begin{abstract}
Juvenile claim on mental health care: sign of crisis. This study is a result of the reflection on the historical meaning of the high juvenile claim on mental health care in public health care units. Through literature about childhood subject, we attempted to recover aspects concerning to its formation since social production. We point out the existence of a childhood crisis - while historical category - in post modern times and we emphasise the presence of some breaks in that childhood reflection. When referring to all children as "children as a whole", we deny that most of them are treated as "children by themselves", for instance, just by their biological maturation. We identified that such crisis in "children by themselves" classes - does not belong exclusively to the post-modern times.
\end{abstract}




\section{Problematizando a questão}

ão inúmeros os estudos ${ }^{6}$ já realizados que demonstram que, - entre a população atendida pelos serviços de saúde mental da rede pública de saúde, a clientela infantil tem representado sua imensa maioria.

Entretanto, ainda que a clientela infantil represente a maioria dos atendimentos realizados nesse setor da saúde (sem levarmos em consideração as extensas listas de espera), são raros os estudos e/ou pesquisas, de caráter epidemiológico ${ }^{7}$, relativos a população infantil que busca atendimento psicológico em instituições públicas.

Com esse caráter, um dos raros estudos realizados no Brasil, considerado uma referência epidemiológica por contemplar uma amostra representativa da população e a formulação de uma metodologia específica e adaptada à realidade brasileira, é a investigação de autoria de Almeida Filho (1985), realizada através do Programa de Saúde Mental da Faculdade de Medicina da Bahia (UFBA).

De acordo com esse autor, a prevalência de desordens mentais na infância é estimada em $23,2 \%$, sendo que, desse valor, $10 \%$ são considerados casos moderados e severos (necessitando de assistência especializada) e 13,2\% são considerados casos leves ou duvidosos, dispensando assistência especializada. Foram estabelecidas taxas para cinco categorias, de acordo com o diagnóstico sindrômico, entre as quais a categoria "desordens neuróticas e psicossomáticas" obteve a taxa mais elevada $(15,2 \%)$, seguida de "retardo mental" e "transtornos orgânico-cerebrais", ambas em torno de 2,5\%, e as categorias "transtornos do desenvolvimento" e "outros", mente.

A considerar as indicações desse estudo e, se tomarmos como exemplo um município de 267.000 habitantes, cuja população infantil é estimada em 41.000 , teremos cerca de 4.100 crianças que, provavelmente, necessitam de atendimento especializado em saúde mental.

Pela situação da saúde pública no Brasil, não é difícil perceber que são frágeis as possibilidades de atender toda essa demanda. Mas, além da falta de serviços para atendê-la, há uma outra questão que deve ser considerada. 
Ao tomarmos como base as queixas apresentadas e os diagnósticos realizados nos serviços de saúde mental da rede pública de saúde percebemos que a grande maioria deles se referem a "problemas de aprendizagem" "ou escolares, comprometimentos esses que não necessariamente exigem intervenção de um profissional de saúde mental. Assim, é possível que, além de não existir suficiente oferta de serviços para atender àquelas crianças que, provavelmente, necessitam de atendimento especializado em saúde mental, a maior parte do tempo do profissional é absorvida em atendimentos, muitas vezes, dispensáveis. Sob esse prisma, podemos supor que o profissional de saúde mental, ao se ocupar com casos que dispensariam sua intervenção, acaba contribuindo para que haja um déficit ainda maior em relação à demanda infantil que realmente necessitaria de assistência psicológica. E outra: ao atender às "dificuldades escolares" no âmbito dos serviços de saúde mental, tal profissional reedita, assim, questões que atravessaram o século e atualmente são a prova mais contundente da ineficácia da medicalização/psicologização de dificuldades escolares (Boarini, 1996).

Sem entrar no mérito de tal questão vamos, a partir dela, tentar destacar um outro aspecto desse fenômeno, que objetivamos com a seguinte ponderação: por uma questão cultural, entre outras, que não cabe discutir neste estudo, o encaminhamento ${ }^{10}$ da criança ao serviço de saúde mental traz em si o preconceito ou estigmatização, tanto por parte de pais e professores, como também - muitas vezes - por parte do próprio profissional de saúde mental. Dito de outra forma, a criança é encaminhada ao serviço de saúde mental porque supostamente tem um problema, mas no momento em que é atendida podem surgir novos problemas, de ordem preconceituosa.

Refletindo sobre esse fato, não é difícil perceber que a situação se desenha nada interessante para a criança. Em outras palavras: quando percebemos que um grande contingente de crianças "batem à porta" dos serviços de saúde mental, qualquer que seja o prisma pelo qual se avalie, em nossa leitura há a indicação de que algo não vai bem para a infância, e isso não deve ser desconsiderado.

Diante dessa problemática, estamos nos propondo a refletir sobre o significado histórico da alta demanda infantil que busca os 
serviços de saúde mental da rede pública de saúde, trabalhando com o pressuposto de que a maior incidência das crianças que buscam tais serviços pertencem às classes populares. ${ }^{11}$

Definimos, ainda, a hipótese de que essa demanda, entre outras situações desagradáveis vividas pela criança, está apontando para uma crise da infância, que, para a criança das classes populares, não é exclusiva da pós-modernidade. ${ }^{12}$

É necessário salientar que, nos limites deste artigo, não iremos discutir políticas públicas de saúde e, nem tampouco, a formação do profissional de saúde mental $^{13}$ ou, ainda, negar a existência de psicopatologia na infância, mas fazer algumas considerações - sob uma perspectiva histórica - da questão da alta incidência de encaminhamentos de crianças aos serviços de saúde mental que, sob qualquer aspecto pelo qual se avalie - de confirmação de psicopatologia ou não - traz custos para a criança, em razão do preconceito por ela sofrido, entre outras questões.

Vale assinalar que, na formulação de nossa hipótese, partimos do pressuposto de que a infância, tal como as demais "idades do homem", é uma criação da sociedade, ao longo de sua história. Nesse sentido, nossas reflexões serão precedidas de pontuações da história, sem a pretensão de esgotá-la em sua riqueza.

\section{Infância: uma categoria histórica}

Abordar a infância como processo histórico não é tarefa simples, pois implica considerá-la como um fenômeno produzido e datado de um certo tempo e, de tal modo, constituído de finitude.

Nesse sentido, Figueira (1985) afirma que nós, seres humanos, temos certa tendência a considerar o mundo que nos rodeia como natural. Tendemos, por exemplo, a considerar a infância, a adolescência, a maturidade, a velhice, enfim, a divisão por faixas etárias como algo que sempre foi assim. Nesse sentido, não vislumbramos a condição de transitoriedade dos fatos e passamos a não enxergá-los como resultantes das ações dos homens, em cada período histórico.

Ao se referir à criança e, particularmente, à historicidade de sua condição específica - a infância - Oliveira (1989), afirma: “Considerar a natureza social do homem, no caso específico da criança, significa 
pensar a criança na relação com a sociedade, com os bens e valores produzidos socialmente, com as novas necessidades que se vão criando" (p. 74).

Portanto, pensar a infância como processo histórico é concebê-la - no bojo das necessidades criadas - como fenômeno eminentemente social e dialético construído em consequiência de uma prática social, em um tempo configurado.

É sob esta ótica - da historicidade - que buscamos apreender alguns aspectos inerentes ao surgimento do conceito de infância, colocando em discussão sua idéia naturalizada, predominante em nossa sociedade.

\section{A produção da infância}

Anteriormente à modernidade, segundo Ariès (1978), inexistia um sentimento ou uma consciência da diferença da criança diante do adulto. Para ele, é mais provável que não houvesse lugar para a infância nas sociedades antigas. O fato é que até o século XII a infância era desconhecida, ou não representada. ${ }^{14}$

Por volta desse período "a criança começaria a sair do anonimato generalizado no qual vivia submergida, ainda que fosse o século XVI ou, mais precisamente, o século XVII que daria conta de expressar o lugar que ela vinha ganhando na consciência social". (Ariès, citado em Oliveira,1989, p. 99).

Para Ariès (1978), essa ausência de consciência da infância até o final da Idade Média se deve ao fato da inexistência de uma concepção de criança como categoria etária específica, pela sua falta de representatividade efetiva nesse momento na sociedade européia. Sua posição é a de que, pelo fato de a morte prematura da criança ser quase inevitável, a representatividade dela era dada pelos limites de sua concreta existência.

Dito de outra forma: se a criança sobrevivia, passava a fazer parte do contexto social, "diluída" entre os adultos. Caso contrário, era simplesmente esquecida ou raramente representada em túmulos da família. $^{15}$

Ao longo dos séculos XV e XVI e, mais precisamente, durante o século XVII, foram surgindo representações de crianças - mesmo daquelas que não sobreviviam. O retrato refletia o espaço que a criança 
ganhava na consciência social e o surgimento de um sentimento novo da sociedade para com ela. Anteriormente, havia algumas representações de crianças, mas com características físicas de adulto, como "adultos em miniatura", identificados a santos, anjos, deuses etc. Foi nesse século também que os retratos de família "tenderam a se organizar em torno da criança, que se tornou o centro da composição" (Ariès, 1978, p. 65). A imagem da criança celeste, angelical e endeusada foi sendo superada pela imagem da criança real, histórica, com determinadas feições, com vestimentas específicas e com uma identidade particular (Oliveira,1989).

Todavia, essa nova mentalidade diante da criança não aconteceu por obra do acaso; adveio das transformações sociais inerentes ao modo de produção capitalista. Nessa nova organização social, descobre-se a criança enquanto força de trabalho. É pelo trabalho da criança, ou melhor, pela exploração dessa mão- de- obra, que a infância é reconhecida, com diferenças, que pontuaremos a seguir, quanto ao gênero e à classe social da qual essa criança era parte.

\section{O privilégio ao sexo masculino}

À medida em que ocorria uma diferenciação da criança diante do adulto (denotada pelas vestimentas específicas, brincadeiras e jogos próprios, e pelo afeto crescente em relação a elas) e se observava a paulatina consciência de um sentimento de infância delineando um mundo próprio para as crianças, passava a ocorrer também uma diferenciação entre os sexos, em que o menino teve sua especificidade de infância reconhecida primeiramente. Esse reconhecimento é referendado por Ariès (1978), que afirma: "O sentimento de infância beneficiou primeiro o menino, enquanto as meninas persistiram mais tempo no modo de vida tradicional que as confundia com os adultos." (p. 81).

Tal particularidade dos meninos em relação às meninas é observada por Ariès (1978) como a rearticulação da questão do sexo e do poder do homem sobre a mulher, reinante na civilização moderna, notadamente masculina.

Outra particularidade conferida aos meninos, em detrimento das meninas, surgiu no costume de freqüentar o colégio: aqueles passaram 
a ter acesso ao conhecimento formal produzido na época, enquanto estas continuaram à margem do saber transmitido pela escola.

Eles (os meninos) começaram a freqüentar em massa os colégios, já no fim do século XVI e início do XVII. O ensino das meninas começou apenas na época de Fénelon ou Mme. Maintenonn, e só se desenvolveu tarde e lentamente. Sem uma escolaridade própria, as meninas eram muito cedo, confundidas com as mulheres, como outrora os meninos eram confundidos com os homens e ninguém pensava em tornar visível através do traje uma distinção que começava a existir concretamente para os meninos, mas ainda continuava inútil no caso das meninas.

(Oliveira,1989, p.109)

\section{O privilégio de classe social}

Para Ariès (1978), concomitantemente com essa contradição de sexo, que acabou refletida no sentimento de infância, também passou a ser articulado o conteúdo de classe nele embutido. Além de surgirem particularidades de criança enquanto criança, passaram a existir particularidades entre crianças de classes sociais distintas. Suas colocações são elucidativas quanto à identificação de tais particularidades:

Se nos limitarmos ao testemunho fornecido pelo traje, concluiremos que a particularização da infância durante muito tempo se restringiu aos meninos. O que é certo é que isso aconteceu apenas nas famílias burguesas ou nobres. As crianças do povo, os filhos dos camponeses e dos artesãos, as crianças que brincavam nas praças das aldeias, nas ruas das cidades ou nas cozinhas das casas continuaram a usar o mesmo traje dos adultos: jamais são representadas usando vestido comprido ou mangas falsas. Elas conservaram o antigo modo de vida que não separava as crianças dos adultos, nem através do traje, nem através do trabalho, nem através dos jogos e brincadeiras. (p. 81 - grifo nosso)

Dessa forma, Ariès (1978) observa uma íntima relação entre o "sentimento de infância" e o sentimento de classe, indicando que algumas práticas (por exemplo, jogos, brincadeiras) foram sendo 
abandonadas por adultos pertencentes à nobreza e à burguesia enriquecida, e conservadas entre as crianças das classes dominantes e os adultos e a crianças do povo. Essas práticas encontravam-se no cerne da distinção de outras práticas (de sobrevivência) que começavam a erigir-se distintamente entre adultos de uma e de outra condição social. Portanto, a distinção entre crianças e adultos vinha acompanhada da distinção de classes. Enfatizando esse aspecto, o autor ainda complementa: "É notável que a antiga comunidade dos jogos se tenha rompido ao mesmo tempo entre as crianças e os adultos e entre o povo e a burguesia. Essa coincidência nos permite entrever desde já uma relação entre o sentimento de infância e o sentimento de classe" (p.124 - grifo nosso).

Assim, a partir do século XVII, a sociedade passa a consolidar essa trajetória da infância, reconhecendo, primordialmente, a condição da criança das classes dominantes. A criança passa, então, a existir como objeto de conhecimento e de afeto e a ser pensada a partir de alguns referenciais, tais como: improdutividade, irresponsabilidade, fragilidade, dependência, inocência, ternura, vulnerabilidade, alheamento à problemática das relações sociais e políticas etc. (Oliveira, 1989).

A consolidação definitiva viria no século XVIII, quando a classe burguesa - já firmada como dominante - passa a reconhecer as especificidades da criança como algo posto desde sempre na história, inclusive indo além de apenas um reconhecimento dessas especificidades. Nessa nova sociedade, são constituídas instâncias para seu cultivo e conhecimento através das práticas (pedagogia, medicina da criança, psicologia da criança etc.) que almejam um conhecimento científico e teórico sobre ela. Mello Neto e Martinez.(1994) relatam algumas conseqüências diretas para a criança nesse processo de distinção da mesma do cenário comum da sociedade, acentuando que tal distinção veio "...acompanhada do enclausuramento dos pequenos em regiões sociais bem definidas, como a família e o colégio" (p. 16). Segundo esses autores, esse afastamento das relações sociais mais amplas “...permitiu a existência da criança como objeto de investigação, de 
forma a possibilitar a constituição de saberes sobre a infância" (p. 16).

Assim, recuperarmos a existência de um significado para a infância na modernidade é, ao mesmo tempo, entender que o seu anonimato na consciência da pré-modernidade não se devia somente, ou primordialmente, às condições de morte prematura ou de poucas chances de sobrevivência da criança na época, mas à ausência da idéia geral de criança e de infância, predominante em sociedades anteriores ao modo de produção capitalista.

\section{Delineando algumas rupturas}

Dessa forma, o sentimento de infância passou a existir e a ser sustentado a partir de determinado período e dentro do enquadramento de uma classe social na qual a criança foi reconhecida como objeto de conhecimento, e a partir de outras "determinações que foram revelando mais a natureza social da criança e construindo a condição da infância no bojo das forças do desenvolvimento e da apropriação dos bens socialmente construídos para a sociedade em geral" (Oliveira,1989, p. 91).

$\mathrm{Na}$ essência desse progressivo reconhecimento, as contradições de classe - que são um corolário da sociedade moderna - estiveram sempre presentes, determinando rupturas significativas nas relações sociais. Tais rupturas (sutilmente pontuadas por Ariès) denotam o corte entre ser criança à luz da especificidade construída e ser apenas criança enquanto condição de maturação biológica.

Segundo Oliveira (1989) “A existência desse corte determina a criança com o gozo das condições para viver de determinada forma seu tempo de criança e crianças excluídas dessa condição. Crianças-infantes e crianças-tão-somente" (p. 91, grifo nosso).

A mesma autora ainda pontua que, se não considerarmos essa ruptura, a infância - enquanto construção histórica - perde sua concretude e torna-se "uma mistificação, uma ideologia, um dado eterno, natural, próprio à espécie, como costuma perpassar o senso comum” (p. 92).

Portanto, estender esse sentimento de infância a todas as crianças é tratar a infância como um dado universal, a-histórico e, portanto, ideologizado. 
Diante disso, faz-se necessário observar e captar, nas relações histórico-sociais, os elementos diferenciadores pois os riscos de se pensar ideologicamente a infância estariam em que a ideologia é uma mistificação da realidade e, por isso, insuficiente do ponto de vista da objetividade do fenômeno. Ela se explica apenas em suas ligações causais ou por suas formas gerais. Nesse sentido, se tomarmos como objeto de conhecimento e análise a infância como dado geral - e universal -, estaremos negando que "tal forma de conhecer leva consigo limites determinados pela posição de classe do sujeito que conhece" (Oliveira,1989, p. 69).

Nesse sentido, mais que reconhecer a falta de especificidade da criança que é apenas criança em dado momento histórico (identificado como a pré-modernidade) devemos perceber as nuances que permeiam as novas concepções de criança surgidas na Idade Moderna, quando se instalam, "dentro de um mesmo momento histórico, contornos diferentes em estratos diferentes da população de crianças" (Oliveira,1989, p. 96).

\section{A criança: do público ao privado}

Pelos estudos já realizados e, neste texto indicados, afirma-se que o surgimento da especificidade da infância, a partir do século XII, seguiu uma trajetória que vai do público ao privado, ou seja, de uma vida indiferenciada da criança na sociedade como um todo a um contexto particular dentro de uma constituição familiar particularizada.

Para Oliveira (1989), enfatizar essa trajetória

...não significa desconsiderar a dialética público-privado que tece cada uma dessas instâncias, mesmo quando referidas, cada uma, pontuadamente. Quando a criança vive relações do ordenamento do particular, da família, vive-as sob determinações também do público, da sociedade, expressas no interior da família, reeditando-se assim a natureza social do homem que não se individualiza senão em sociedade. As próprias regras que pais e filhos privam no interior da sua casa são tecidas por uma substância social, tal como o são os bens consumidos individualmente, mas postos por uma produção coletiva (p. 119). 
O que extraímos dessa análise é a necessidade de identificar a condição particular da criança, primeiramente "diluída" num contexto social amplo e, mais tarde, inserida/particularizada no contexto familiar moderno.

Ariès (1978) destaca a estreita relação entre o surgimento do sentimento de infância e de um sentimento de família, pois, na ausência deste último, a vida indiferenciada da criança diante dos adultos teciase em espaços também indiferenciados (nas ruas, nas casas, nas festas etc.). Até o século XVII, a família confundia-se com os grandes grupos, inexistindo limites rígidos entre o público e o privado.

Algumas observações de Ariès (citado por Oliveira, 1989) sobre as moradias até o século XVII são ilustrativas quanto ao caráter pouco privativo e à forma ainda pouco particularizada das famílias: "As casasgrandes, particularmente no século XVII, abrigariam além da família conjugal, toda uma multidão de criados, clérigos, caixeiros, aprendizes, auxiliares e raramente um ou outro parente" (p. 121).

A própria geografia dos cômodos das moradias denotava o sentido pouco privado da casa, a qual desempenhava uma função pública. Nessa sociedade com poucos espaços sociais, ela era um dos únicos lugares onde os amigos, clientes, parentes e protegidos podiam se encontrar e conversar. Os cômodos eram mais especializados do ponto de vista profissional do que doméstico. Nas mesmas salas onde se comia, também se dormia, se dançava, se trabalhava e se recebiam visitas. Nesse contexto de pouca privacidade, Ariès (1978, pp. 258-260) identifica a relação da criança com a família e desta com a sociedade:

... a criança desde muito cedo escapava à sua própria família, mesmo que voltasse a ela mais tarde, depois de adulta, o que nem sempre acontecia. A família não podia, portanto, nessa época, alimentar um sentimento existencial profundo entre pais e filhos. Isso não significa que os pais não amassem seus filhos: eles se ocupavam de suas crianças menos por elas mesmas, pelo apego que lhes tinham, do que pela contribuição que essas crianças podiam trazer à obra comum, ao estabelecimento da família. A família era uma realidade moral e social, mais do que sentimental (p. 258-260, grifos nossos). 
Esse panorama social foi se modificando aos poucos e, à medida que a sociedade se transformava - com o advento da revolução industrial - também a família lentamente passava a estruturar-se de forma a configurar-se num espaço cada vez mais privado, capaz de garantir a intimidade de seus membros e a defesa das funções privadas estabelecidas pela nova sociedade de classes.

Como consequiência desse "afastamento" do meio social, as moradias passaram a ser construídas de tal modo que privilegiassem a intimidade e demarcassem os limites entre o extra e o intra-familiar. Esse movimento veio acompanhado de crescentes preocupações com a higiene, a saúde e a educação das crianças em cada família. Tais preocupações já indicavam a manifestação do sentimento de infância e, portanto, de um afeto particularizado à criança como membro de uma família específica: como sujeito do privado.

Para Ariès (1978), esse movimento teria dado à criança, por volta do século XVII, o status de uma "personagem consistente" no interior da família. Essa especificidade teria se estruturado como reflexo de uma transformação considerável na família, fazendo que esta se concentrasse na criança. Por sua vez, essa intimidade realçaria, cada vez mais, as relações afetivas entre pais e filhos.

Tratando da origem e constituição da família desde o estágio selvagem até a família moderna - tal qual a concebemos -, Engels (s.d.) mostra o percurso e as determinantes sociais que acarretaram suas formas de constituição em diferentes épocas ${ }^{16}$. Nesse percurso ele recupera historicamente a condição de vinculação das formas de família e a formas de organização das sociedades. Assim, se a sociedade pré-moderna não se caracterizava pela rígida distinção de classes assentada na propriedade privada, a família não se distinguia da sociedade enquanto reflexo dessa divisão, que no século XVIII se faria sentir e refletir na composição da mesma.

De acordo com Engels (s.d.), as raízes da família moderna (leia-se monogâmica) estão na antigüidade grega, e o seu triunfo definitivo na modernidade. Ela é baseada "no predomínio do homem; sua finalidade expressa é a de procriar filhos cuja paternidade seja 
indiscutível; exige-se essa paternidade indiscutível porque os filhos, na qualidade de herdeiros diretos, entrarão, um dia, na posse dos bens de seu pai" (p. 52).

Engels (s.d.) é categórico ao identificar o papel da família na nova divisão da sociedade em classes - permeada pela divisão do trabalho. Para ele, "a família individual principiou a transformar-se na unidade econômica da sociedade" (p. 130).

Nessa nova forma de organização da sociedade, a família passou a tomar, efetivamente, a seu encargo, a orientação e a proteção da infância, tornando-se a mediadora entre as exigências sociais e as particularidades da criança e recebendo a delegação de formar o modelo de criança e o conteúdo de infância condizentes com as aspirações da sociedade moderna.

\section{A infância na pós-modernidade}

Mas será que esse modelo de infância ainda persiste? E a criança das classes populares? Ela chegou a integrar esse "projeto moderno" de infância?

Se tomarmos como base a constituição histórica dos fatos, de que a prática precoce do trabalho desgastante ou, ainda que seja, de pequenos serviços que a criança realiza fora da família, é uma forma de garantir sua sobrevivência e, muitas vezes, a de sua família, certamente perceberemos que o papel desta como "locus do cultivo da intimidade" se enfraquece, e que o significado da criança como ser do privado também não encontra respaldo. Pensando por esse prisma, entenderemos não ser difícil constatar que a infância, concebida como sinônimo de fragilidade, dependência, improdutividade etc., é reconhecida apenas nas classes dominantes, embora a rigor de $1 \mathrm{ei}^{17}$ a idéia de infância tenha sido reconhecida para todas as crianças das classes populares.

Para a "criança em si": alguns sinais de crise

A breve reconstrução da trajetória da criança e da família realizada até o momento nos permite perceber que a condição de especificidade da criança - a infância - encontrou sua síntese na sociedade moderna, 
sendo modelada essencialmente para as crianças das classes dominantes.

Mas qual o papel ou a função reservada à criança nessa sociedade?

Sob esse aspecto, Oliveira (1989) observa que a criança na sociedade moderna cumpre a sutil função “...de fortalecer a infância como tempo específico, dominado por práticas especiais que girem em torno da formação e do lazer, da proteção e do carinho, do desfrute das conquistas sociais capazes de anteciparem para a criança o homem livre, igual, proprietário e útil à sociedade - do projeto burguês de infância" (p. 156, grifo nosso).

Calligaris (1994), sob outra perspectiva teórica, enfatiza que, na imagem da criança, foram condensados os ideais de felicidade a serem buscados pelo homem moderno, já que as "garantias" de felicidade até então afiançadas pelos laços estabelecidos entre servos e senhores feudais na Idade Média - não mais vigoravam. Assim, “...a idéia de felicidade mudou de rumo: aos poucos parou de se alimentar na calma de uma ordem estabelecida ou na visão futura de novas relações sociais, para ser um direito do indivíduo. Direito cujo exercício não é nunca perfeito, o que se torna um dever para os herdeiros: nossas crianças" (p. 4, grifo nosso)

Portanto, para Calligaris, mesmo esse projeto moderno de infância, concatenado pela imagem da criança bonita, saudável, alegre, cheia de energia e imaginação, atualmente esbarra em condições concretas de vida, permeadas por extremas desigualdades sociais, por crescentes manifestações de violência fora e dentro de casa. $O$ sonho e a fantasia são cada vez mais articulados às práticas de consumo, que são oferecidas como tentativa de ressurreição da antiga promessa de felicidade eterna, abandonada pelo homem moderno.

Essa promessa ressurge hoje, condicionada à aquisição de bens produzidos pelo capital, e a criança se mostra um alvo forte do mercado de consumo e também um eficiente incentivador desse mercado, como modelo de consumo. "Milímetro a milímetro, a sociedade industrial coloca a criança numa relação de adaptação recíproca com artefatos cuja eficácia torna ridículo qualquer esforço de satisfação produzido pelos pais" (Jerusalinski e Tavares, 1994, p. 5). 
Desse modo, a criança, como sujeito de relações sociais amplas, representa para a sociedade capitalista um consumidor de produtos variados, bem como um veiculador de venda de produtos tidos como específicos para crianças no momento em que "é atirada nessa teia de relações da atual sociedade moderna e posta fazendo valer seu charme infantil, os seus traços específicos que parecem curvar, emocionalmente, a sociedade aos seus encantos" (Oliveira,1989, p. 11).

Jerusalinski e Tavares (1994, p. 5) observam que, cada vez mais condicionada à aquisição de objetos (que não garantem a satisfação almejada), a imagem da criança feliz vai-se esvaindo e sendo aos poucos substituída pela realidade da criança sujeita a atos de violência e/ou abusos sexuais, abandonada fora e dentro de casa, delinqüente e exterminada nas ruas e praças públicas, da criança depositária dos conflitos e tensões sociais de uma sociedade em crise. ${ }^{18}$

Nesse sentido, Calligaris (1994) acentua que o "reino encantado" da infância já não encontra mais espaço para existir enquanto projeto da modernidade, pois já não possui enquadramento possível dentro do contexto social moderno: o contexto que o criou. Nas suas palavras: "A infância talvez tenha sido a mais duradoura das utopias concebidas pela modernidade. Como tantos outros ideais imaginados nos últimos 200 anos, o do mundo maravilhoso das crianças também entra em crise na era pós-industrial e pós-moderna.” (p. 4, grifo nosso)

Essa afirmação encontra sustentação no expressivo aumento da violência contra crianças, da criminalidade infantil e do "abandono e o sacrifício a que estão sujeitas no centro e na periferia do capitalismo. $\mathrm{O}$ excesso de produtos tecnológicos destinados ao seu consumo não fazem hoje mais do que explicitar o outro lado desse sonho: uma caricatura perversa do próprio mundo adulto" (p. 4, grifo nosso).

\section{Para a "criança tão-somente": a permanente crise}

Iniciamos este artigo propondo uma reflexão sobre o significado histórico da alta demanda infantil aos serviços de saúde mental, tendo como pressuposto que esses serviços atendem crianças, em sua maioria, advindas das classes populares. Tecemos a hipótese de que essas 
crianças vivem uma permanente crise - enquanto infância - e não somente uma crise nascedoura com o advento da sociedade pósmoderna.

Embora atualmente se faça sentir, por meio de denúncias, movimentos de proteção, estatutos etc., uma crescente preocupação com as precárias condições da infância, entendemos que tal problemática não é nova. Através de alguns escritos de Marx (1985) sobre a legislação fabril inglesa, podemos perceber que a exploração da criança das classes populares e, portanto, a inexistência da infância isenta de violências, do trabalho, de responsabilidades do mundo adulto, ou seja , a inexistência da "infância feliz", para esse segmento social, não é uma questão apenas da atualidade.

A comissão de inquérito de 1840 tinha feito revelações tão terríveis e revoltantes e provocado tanto escândalo em toda a Europa que o Parlamento foi obrigado a salvar sua face, promulgando a lei sobre o trabalho nas minas (Mining Act) de 1842, que se limitava a proibir o trabalho embaixo da terra das mulheres e crianças com menos de 10 anos. Em 1860 foi promulgada a lei de inspeção das minas que previa a fiscalização delas por funcionários especialmente nomeados para esse fim e proibia o emprego nelas de menores entre 10 e 12 anos, excetuados os que possuíssem um certificado escolar ou freqüentassem a escola durante certo número de horas. (p. 566, grifo nosso)

De acordo com Marx (1985), apesar da aparente pobreza que apresentavam em seu conjunto, as disposições da lei fabril fizeram da instrução primária condição indispensável para o emprego de crianças. Naquela época, isso representou um avanço, pois ela se propunha proteger a criança da exploração tanto dos donos das fábricas, como dos "pais ou outras pessoas que tinham sob sua vigilância a criança (...) ou extraiam vantagens diretas do trabalho delas" (p. 566). Marx (1985) salienta que apesar desse pequeno avanço em termos de legislação, essa lei "ficou sendo letra morta" devido ao pequeno número de inspetores nomeados para fiscalizar as minas e aos escassos poderes que lhes foram concedidos, entre outras causas. 
Versando sobre o trabalho forçado e a exploração das crianças, em meados de 60, no século passado, o relatório da Child. Empl. Comm. de 1866, assinado por um inspetor de fábrica, conclui:

O sistema da exploração sem limites do trabalho infantil em geral e do trabalho a domicílio em particular é mantido pelos pais que exercem sobre seus novos e tenros rebentos uma autoridade arbitrária e nefasta, sem freio e sem controle (...). Os pais não devem possuir o poder absoluto de transformar seus filhos em simples máquinas de produzir por semana determinada quantia em salário (...). Crianças e jovens têm um direito à proteção da lei contra os abusos do poder paterno, os quais destroem prematuramente sua força física e os degradam intelectual e moralmente (Marx,1985, p. 560, grifo nosso).

A preocupação com a existência e as péssimas condições do trabalho infantil também se fazia sentir no Brasil, já no final do século XIX:

A partir da fase de industrialização incipiente, a presença de crianças e de adolescentes no trabalho das fábricas e oficinas em São Paulo, predominantemente no setor têxtil, resulta em reações de caráter crítico à utilização e exploração dessa mão-de-obra no trabalho industrial, veiculadas sobretudo através da imprensa (...). Na década de 1890, a Repartição de Estatística e Arquivo do Estado de São Paulo esclarece, em relatório, que os menores representam, com relação ao conjunto de atividades consideradas - indústrias do vestuário, de fósforos, de fumo, têxteis, alimentícias, fundições e oficinas mecânicas, fábricas de móveis, além de serrarias, tipografias e olarias entre outros estabelecimentos, num total de $64-, 15 \%$ do total da mão-de-obra empregada, representando, no têxtil, cerca de $25 \%$ do total de mãode-obra absorvida por esse setor (Moura, 1995, pp. 112-114).

Dessa forma, o que parece novo, na verdade revela-se como reedição de situações similares já vivenciadas pela criança desde o início da modernidade. O inédito talvez esteja, grosso modo, na constante divulgação de tal realidade. ${ }^{19}$ 
... em todo o mundo, é notório o movimento em busca de mais visibilidade para o mundo infanto-juvenil. Tal empresa tem revelado aspectos vis, que eventualmente custamos a reconhecer: trabalhos forçados, extermínio, abandono, criminalidade, prostituição, analfabetismo, sobrevida nas ruas, nas instituições, no lixo ${ }^{20}$, dependência de drogas, extirpação de órgãos, etc.. (Santos, 1994, p. 40)

Santos (1994) acentua que tal visibilidade se reflete no confronto com essa realidade, na qual "os núcleos, conselhos, entidades, têm, por todo o planeta, sistematicamente se organizado buscando, imediatamente e a longo prazo, proteger a infância e a adolescência dos pais, dos professores, do crime organizado, em suma, de toda a sorte de violentadores" (p. 41).

A mesma autora ainda postula - referindo-se à criança brasileira que o lugar comum da "criança-futuro do Brasil" já não faz eco do discurso à prática pois esta depõe contra qualquer negação ou mascaramento da situação.

$\mathrm{Na}$ afirmação de Santos, dois pontos há que se ponderar. Em primeiro lugar, não obstante os esforços empreendidos por vários segmentos da sociedade no sentido de buscar a melhoria das condições de vida de milhões de crianças no Brasil e em todo o mundo, a situação se desenha cada vez mais desinteressante para elas. E, nesse sentido, fazemos nossas as palavras de Silva (1996:

Hoje, quando as forças produtivas capitalistas já se desenvolveram a um nível universal, a recorrência ao cidadão para solucionar problemas sociais como a fome e a miséria não parece propriamente eficaz. Pelo menos não em se mantendo as relações sociais de produção como estão, pautadas pelos interesses individuais, onde o cidadão é um ser genérico situado num plano ideal e acima das desigualdades sociais (p. 180).

Por outro lado, consideramos que não só existem muitas possibilidades de negação ou mascaramento dessa realidade, como também poderes instituídos para isso. Podemos exemplificar com o fato de que muitas instituições, como a própria escola ou até o serviço de 
saúde mental, oferecem à criança - mesmo sem o perceber - o caminho da estigmatização, quando identificam nela o responsável por fracassos que, especificamente, não são dela.

Não é nosso propósito polemizar a questão em torno da escola e menos ainda no sentido de identificá-la como responsável pelas mazelas da sociedade. Trabalhamos, porém, dentro das possibilidades colocadas por Brandão (1985), de que muitas vezes a educação consagra a desigualdade que deveria destruir e afirma como idéia o que nega como prática. Esta afirmação nos faz recuperar Engels (s.d.) que, em meados do século passado, ponderava:

Quando nasce nos homens a consciência de que as instituições sociais vigentes são irracionais e injustas, de que a razão se converteu em insensatez e a bênção em praga, isso não é mais que um indício de que nos métodos de produção e nas formas de distribuição produziramse silenciosamente transformações com as quais já não concorda a ordem social (p. 320).

Refletindo sob essa perspectiva, Tessaro (1993), ao se referir às crises por que passam atualmente as instituições existentes na sociedade capitalista (religião, casamento, família etc.), afirma que essas crises se manifestam quando os "mecanismos que, até então, davam certo, parecem, repentinamente, não mais funcionar". Sob essa ótica, as revelações formuladas pela imprensa, associações, entidades religiosas etc. se colocam como denúncia de uma crise para a infância, e a voz isolada da criança (através do sintoma) pode se constituir, em muitos casos, como manifestação particular de tal crise.

Diante disso, insistimos nas pontuações de Oliveira (1989) de que ao tratarmos ideologicamente a infância estamos lidando com tal fenômeno sob a forma de generalidade esvaziada - não reconhecendo as rupturas ou cortes presentes na idéia de especificidade configurada para a criança(a infância). Torna-se, assim, inviável qualquer tentativa de transformar a situação crítica vivida permanentemente pela criança das classes populares e, mais modernamente, por todas as crianças, já que essa crise se produz no interior e pelas relações estabelecidas socialmente e não externamente a elas. 
A criança - enquanto categoria histórica - está presente nas relações sociais através das idéias ou imagens que são feitas dela e, essencialmente, através de sua inserção social, seja como "criança infante" tida como frágil, imatura, dócil, dependente, improdutiva etc., seja como "somente criança" que é pensada - na forma da lei e do discurso - como a primeira, mas tratada efetivamente - na prática como rebelde, indócil, "trabalhadora" (ou vagabunda?), inferior, subversiva, malandra, deficiente, ou até - de acordo com as queixas apresentadas nos serviços de saúde mental - como portadora de transtornos mentais, quando não é o caso.

Temos, assim, que pelo grande contingente de crianças geralmente advindas das classes populares - que são encaminhadas e atendidas ou colocadas em intermináveis listas de espera e, pelo preconceito que sofrem por parte do meio que as rodeia, tal assistência, sendo prestada ou não, acaba se colocando, na grande maioria das vezes, como mais um desalento para a criança. Em virtude da estigmatização que esta sofre por parte de quem a encaminha e, muitas vezes, até por parte de quem a atende (confirmada ou não como portadora de transtorno mental), faz com que o atendimento no serviço de saúde mental, na essência, uma possibilidade de ajuda ou solução, tansforme-se em mais um problema a ser enfrentado pela criança, dentre tantos outros vividos pela infância das classes populares.

Dessa forma, ao nos referirmos a todas as crianças como "criançasinfantes", estaremos negando algumas rupturas existentes no âmago dessa questão.

\section{Considerações finais}

Iniciamos este artigo propondo uma reflexão sobre o significado histórico da alta demanda infantil pelos serviços de saúde mental, tendo como pressuposto que esses serviços atendem crianças, em sua maioria, advindas das classes populares. Tecemos a hipótese de que essas crianças vivem uma permanente crise - enquanto infância - e não somente uma crise nascedoura com o advento da sociedade pósmoderna, e a arbitrariedade que se observa nesses encaminhamentos/ atendimentos $^{21}$ acentua, ainda mais, essa crise. 
Ao final desta trajetória, nos sentimos à vontade para reafirmar que, inserida no bojo das contradições inerentes a uma sociedade de classes, a infância, enquanto produção dessa sociedade, é reconhecida teoricamente para todas as crianças e, explicitamente reivindicada - no discurso - e implicitamente negada - na prática -, para a grande maioria das crianças pertencentes às classes populares. Dito de outro modo: percebe-se uma grande lacuna entre o discurso e a prática e, à medida que ocorrem formas de preencher tal lacuna (com núcleos de proteção, estatutos, denúncias, declaração de direitos etc.), mais lacunas vão se formando.

Como conclusão, entendemos que, nesse jogo de forças não reconhecido e não tratado explicitamente, a idéia de infância entra em crise e a criança passa a ser responsabilizada por essa crise - como se ela tivesse nascido à parte das relações sociais e não no interior e a partir de transformações nas mesmas. Tal crise - denotada por violências (abusos, abandonos, agressões etc.) contra a criança em geral, além de extermínio, exploração pelo trabalho, fome, encaminhamentos equivocados de alunos que supostamente apresentam problemas na escola, preconceitos, estigmatização contra as crianças pertencentes às classes populares, em que estas, muitas vezes, passam a ser o "bode expiatório" do fracasso das instituições sociais - depõe contra qualquer possibilidade de garantia de direitos adquiridos ou reivindicação dos mesmos.

Nesse contexto, o sentimento de infância vai ficando cada vez mais distante para toda e qualquer criança e, sobretudo, para a criança das classes populares, mesmo porque, para esta, tal sentimento - de fato - nem chegou a existir.

Restringindo o seu lugar simbólico na família, colocada na posição de ter que dispor a qualquer custo dos objetos sem os quais lhe é impossível se sustentar no discurso coletivo, a criança da pósmodernidade fica capturada numa armadilha violenta: "cada um por si”, onde já não vige mais o "Deus por todos". (Jerusalinski e Tavares, 1994, p. 5) 


\section{Referências}

Almeida Filho, N. de. (1985). Epidemiologia das desordens mentais na infância no Brasil. Salvador: Centro Editorial e Didático da UFBA.

Almeida Filho, N. de, Santana, V. S., \& Mari, J. J. (1989). Princípios de epidemiologia para profissionais de saúde mental. Brasília: Centro de Documentação do Ministério da Saúde.

Ariès, P. (1978). História social da criança e da família. Rio de Janeiro: Zahar.

Boarini, M. L. (1993). Unidades básicas de sáude: uma extensão da escola pública? Tese de doutorado não-publicada, Universidade de São Paulo, São Paulo.

Boarini, M. L. (1996). A formação (necessária) do psicólogo para atuar na Saúde Pública. Psicologia em Estudo, 1, 93-132.

Brandão, C. R. (1985). O que é educação. São Paulo: Brasiliense.

Calligaris, C. (1994, 24 de julho). O reino encantado chega ao fim. Folha de S. Paulo, 24 jul. 1994, Caderno Mais!

Engels, F. (s. d.). A origem da família, da propriedade privada e do estado. In K. Marx \& F. Engels, Obras escolhidas (Vol. 2, pp. 7-143). São Paulo: Alfa-Omega.

Engels, F. (s. d.). Do socialismo utópico ao socialismo científico. In K. Marx \& F. Engels, Obras escolhidas (Vol. 2, pp. 281-336). São Paulo: Alfa-Omega.

Figueira, F. G. (1985). Reflexões sobre a história. Manuscrito não-publicado.

Furtado, J. (Diretor) (1989). Ilha das Flores [Documentário].

Jerusalinski, A., \& Tavares, E. E. (1994, 24 de julho). Era uma vez... já não é mais. Folha de S. Paulo, Caderno Mais!

Marx, K. (1985). O capital (10ª ed.). São Paulo: DIFEL.

Mello Neto, G. A. R., \& Martinez, V. C. V. (1994). A criança como erro, pecado e máquina. Cadernos de Metodologia e Técnica de Pesquisa. Suplemento n. 5, 15-92.

Moura, E. B. B. de. (1995). Infância operária e acidente do trabalho em São Paulo. In M. del Priore (Org.), História da criança no Brasil ( $3^{\mathrm{a}}$ ed., pp. 112-128). São Paulo: Contexto.

Oliveira, M. L. B. de. (1989). Infância e historicidade. Tese de doutorado nãopublicada, Pontifícia Universidade Católica de São Paulo, São Paulo.

Santos, C. M. A. dos. (1994). Crianças e adolescentes: uma questão de visibilidade. In NUCEPEC-UFC/CBIA (Org.), Infância e adolescência em discussão (pp. 3142). Fortaleza: Autor.

Sevcenko, N. (1987). O enigma pós-moderno. In R. C. Oliveira, J. F. dos Santos, N. B. Peixoto, \& M. C. Olalquiaga (Orgs.). A pós-modernidade (pp. 43-55). Campinas: Editora da UNICAMP.

Silva, L. C. da. (1996). Solidariedade e individualismo nas campanhas pró-cidadania. Psicologia em Estudo, 1, 171-183.

Tessaro, S. M. P. (1993). O (des)casamento burguês: enfim... só(s)? Dissertação de mestrado não-publicada, Universidade Estadual de Maringá, Maringá.

Wolf, S. M. R. (1988). Alguns dados sobre a caracterização da clientela do centro de psicologia aplicada da UNESP. Perfil, 1, 78-96. 
Notas ${ }^{1}$ Artigo extraído da monografia intitulada "A demanda infantil à saúde mental: reflexo de uma crise?" de autoria de Roselânia Francisconi Borges, sob orientação da Dra. Maria Lucia Boarini e apresentada à Universidade Estadual de Maringá, em 1996.

2 Termo utilizado por Oliveira (1989, p. 97) para se referir à forma generalizada de pensar a criança, sem considerar as determinações sociais e as suas condições particulares em relação à sociedade. Neste estudo nos referiremos a ele com essa perspectiva.

3 Esta denominação foi utilizada por Oliveira (1989) para fazer menção à criança das classes populares, em oposição à denominação "criança infante" das classes dominantes. Ela será por nós utilizada com o mesmo propósito.

4 This expression was used by Oliveira $(1989$, p. 97) to refer to general average thought of children, taking no consideration to some social aspects related to society. In this study we referred to the expression on that view.

5 Also used by Oliveira (1989) to mention the working class children opposed to "juvenile children" from dominant social classes. It is used in this study with the same meaning: 'working class children'.

6 Vide Wolf (1988), Boarini (1993), entre outros.

7 "Uma revisão, ainda que parcial, das publicações brasileiras na área da psiquiatria, neste século, revela um número surpreendente de estudos que se autodenominam epidemiológicos (...); no entanto, uma rápida avaliação dos mesmos revela que (...) apesar de mostrarem uma correta consciência dos seus limites enquanto investigação epidemiológica, utilizam-se, como objeto de estudo, de grupos sob tratamento, impossibilitando, em consequência, a estimativa de indicadores de morbidade psiquiátrica para a população em geral" (Almeida Filho, Santana, \& Mari, 1989, p. 45).

8 Essa categoria engloba os casos de impossível definição diagnóstica e um caso suspeito de psicose infantil.

9 Já discutimos essa questão em outros estudos por nós realizados (Boarini, 1993; 1996).

10 Referimo-nos aos encaminhamentos realizados pela escola, ou por orientação da escola.

11 Oliveira (1989) emprega esse termo para se referir aos indivíduos destituídos dos meios de produção e que, por isso, vendem sua força de trabalho como forma de sobrevivência. No interior deste artigo, é dessa forma que o entenderemos e o utilizaremos. 
106 M. L. Boarini e R. F. Borges

${ }^{12}$ Para Sevcenko (1987, p. 54), pós-modernidade é um conceito que supõe uma reflexão sobre o tempo, mas um tempo não-linear. Ele postula que, para alguns autores, ela corresponderia "ao advento da tecnologia pós-industrial, baseada nos recursos da cibernética e informática”, e, para outros, seria "uma proposta de práticas culturais alternativas... identificadas com o pacifismo, a ecologia, o feminismo, os movimentos de liberação sexual e manifestações afins". Para ele "o pós-moderno sem dúvida traz ambigüidades - aliás é feito delas e deve ser criticado e superado". Ele propõe "a prudência como método, a ironia como crítica, o fragmento como base e o descontinuismo como limite". (grifo nosso)

13 No que tange a formação do psicólogo, já o fizemos em outro artigo. Vide Boarini (1996)

14 Ariès (1978), através de uma análise iconográfica minuciosa (realizada pelo estudo e conhecimento de imagens, retratos, quadros ou monumentos antigos) demonstrou a lenta evolução da mudança de atitudes ao longo dos séculos, enfatizando a trajetória social da criança e da família do fim da Idade Média até a modernidade.

15 Comentando sobre a tradição no País Basco de enterrar em casa, no jardim, a criança morta, Ariés (1978) pondera que "talvez houvesse aí uma sobrevivência de ritos muito antigos de oferendas sacrificiais. Ou será que simplesmente as crianças mortas muito cedo eram enterradas em qualquer lugar, como hoje se enterra um animal doméstico, um gato ou um cachorro?".

16 Engels (s.d.) apresenta um estudo da história da família e das suas diferentes formas de constituição nos diversos estágios de desenvolvimento da humanidade. O leitor interessado nesse tema, necessariamente, deve consultar esse estudo.

17 O princípio $1^{\circ}$ da Declaração dos Direitos da Criança contém a seguinte redação: "A criança gozará todos os direitos enunciados nesta declaração. Todas as crianças, absolutamente, todas sem qualquer exceção, serão credoras destes direitos, sem distinção ou discriminação por motivo de raça, cor, sexo, língua, religião, opinião política ou de outra natureza, origem nacional ou social, riqueza, nascimento, ou qualquer outra condição, quer sua ou de sua família" (Declaração dos Direitos da Criança, ONU, 20/11/1959).

18 Diariamente, via de regra, encontramos, na imprensa comum, manchetes com o seguinte teor: "200 milhões de crianças trabalham em todo o mundo" (Fonte: ONU/ Time)/ "100 mil atos de violência são vistos por crianças na TV 
antes de entrarem para o $1^{\circ}$ Grau nos EUA"(Fonte:American Psychological Association)/"28 crianças em 1000 morreram antes de completar 1 ano no Brasil em 1993" (Fonte: Pastoral da Criança-CNBB)/" $40 \%$ foi o quanto cresceu o número de crianças vítimas de abuso sexual nos EUA entre 1985 e 1991"(Fonte: National Commitee for Prevention of Child Abuse)." (Folha de São Paulo, 24 de julho de 1994).

19 A título de ilustração, selecionamos algumas manchetes, dentre tantas recentes, retiradas de jornais de circulação nacional que nos fornecem alguns indícios das condições da infância das classes populares: "CRIANÇAS FALAM SOBRE O TRABALHO: RELATOS MOSTRAM GRANDE ESFORÇO FÍSICO, FALTA DE PROTEÇÃO E VÁRIAS IRREGULARIDADES". (Fonte: Gazeta do Povo, 29 set. 1996); "AUMENTA A PROSTITUIÇÃO INFANTIL” (Fonte: O Estado do Paraná,12 out. 1996); "FOME MATA 17 CRIANÇAS DOS SEM-TERRA: CAIXÕES FUNERÁRIOS (da prefeitura) PARA 1 ANO DURAM APENAS 11 DIAS" (Fonte: Gazeta do Povo, 12 out.1996); OLARIAS EMPREGAM CERCA DE 800 'CRIANÇAS DO BARRO': MENORES DE 14 ANOS QUE TRABALHAM SÃO 3,8 MILHÕES" (Fonte: Folha de S.Paulo, 27 out. 1996); "CRIANÇA BURLA GUARDAS E COME EM LIXÃO: ATERRO SANITÁRIO DE SÃO PAULO É FONTE DE ALIMENTOS PARA 80 FAMÍLIAS DE FAVELA NA ZONA NORTE DA CIDADE" (Fonte: Folha de S.Paulo, 30out. 1996); "PERNAMBUCO ENTERRA 'ZÉ NINGUÉM': PAÍS FANTASMA, FALTA DE REGISTRO DISTORCE ÍNDICES DE MORTALIDADE INFANTIL" (Fonte: Folha de S.Paulo, 17 nov. 1996); "VERBA DE RAÇÃO ACABARIA COM FOME INFANTIL: OS CERCA DE R\$ 350 MILHÕES GASTOS ESTE ANO PARA TRATAR CÃES E GATOS DARIAM PARA ALIMENTAR 1 MILHÃO DE CRIANÇAS DESNUTRIDAS NO PAÍS" (Fonte: Folha de S.Paulo, 18 nov. 1996); "MORTE DE BEBÊS FAZ MINISTRO IR AO CEARÁ: MINISTÉRIO DESCARTA INFECÇÃO COMO CAUSA DAS MORTES DE 51 RECÉM-NASCIDOS EM NOVEMBRO" (Fonte: Folha de S. Paulo, 22 nov. 1996).

${ }^{20}$ O documentário "Ilha das Flores", de Furtado (1989), oferece um panorama sobre a utilização de aterros sanitários como fonte de sobrevivência.

21 Discutimos essa questão em nosso estudo "Unidades básicas de saúde: uma extensão da escola pública?” (Boarini,1993). 
108 M. L. Boarini e R. F. Borges

Maria Lúcia Boarini é professora adjunta do Departamento de Psicologia da Universidade Estadual de Maringá, PR. Doutora em Psicologia pela Pontifícia Universidade Católica de São Paulo. Endereço para correspondência: Departamento de Psicologia, Universidade Estadual de Maringá, Av. Colombo, 5790, 87.020-900, Maringá, PR. Roselânia Francisconi Borges é psicóloga e especialista em Saúde Coletiva pela Universidade Estadual de Maringá, PR. 